\title{
An Unusual Case of Multiple Food Allergies Comorbid with Multiple Chemical Sensitivity: A Case Report
}

This article was published in the following Dove Press journal: Journal of Asthma and Allergy

\author{
Veronica Storino (D) \\ Juliana Muñoz-Ortiz $\mathbb{D D}^{2}$ \\ Valeria Villabona-Martinez $\mathbb{I D}^{3}$ \\ Juan Diego Villamizar- \\ Sanjuán $\mathbb{D}^{3}$ \\ William Rojas-Carabali (D) $^{3}$ \\ Alejandra de-la-Torre $\mathbb{D}^{3}$ \\ 'Faculty of Medicine, Universidad de los \\ Andes, Bogotá, Colombia; ${ }^{2}$ Escuela \\ Barraquer, Research Group, Escuela \\ Superior de Oftalmología, Instituto \\ Barraquer de América, Bogotá, \\ Colombia; ${ }^{3}$ Neuroscience Research \\ Group "NeURos", Escuela de Medicina \\ y Ciencias de la Salud, Universidad del \\ Rosario, Bogotá, Colombia
}

Purpose: To report the case of a patient with multiple food allergies comorbid with multiple chemical sensitivity (MCS) who was misdiagnosed on various occasions, resulting in a negative impact on the patient's personal and social life.

Case Report: We present the case of a 43-year-old Colombian women with multiple food allergies concomitant with MCS. Symptoms started with a mild reaction to insecticides, car exhaust smoke, and perfumes and gradually evolved into a severe reaction to her environment. She also presented recurrent episodes of clinical reactivity to foods and persistent elevated IgE levels, as well as several life-threatening anaphylactic reactions. Alternative and allopathic therapies were applied, but her symptoms persisted. Various diagnoses were made before the definitive diagnosis.

Conclusion: MCS is an unusual entity of unknown pathophysiology that can, on rare occasions, coexist with food allergies. Early recognition and multidisciplinary treatment are required as these entities have a major impact on the patient's quality of life. We present the first Latin American case regarding the association of the two diseases.

Keywords: type I hypersensitivity, idiopathic environmental intolerance, environmental exposure, food allergy

\section{Introduction}

Multiple chemical sensitivity (MCS) is currently included in the broader definition of idiopathic environmental intolerance ${ }^{1}$ and is an acquired disorder with multiple recurrent symptoms associated with exposure to diverse environmental factors at concentrations significantly lower than those considered toxic for the general population. ${ }^{2}$ MCS is not a well-established disease within the medical literature or medical community, and a number of medical providers have identified MCS as a somatization disorder. ${ }^{3}$ In 1987, Cullen introduced the term $\mathrm{MCS}^{4}$ and proposed diagnostic criteria for the disease, ${ }^{1-3,5}$ which were approved and published in 1999 as the Nethercott consensus criteria. ${ }^{6,7}$

Although MCS does not generate a specific clinical picture, these patients have multiple symptoms that include headache, dizziness, decreased concentration, odor sensitivity, fatigue, and skin lesions, which lead to changes in behavior to avoid the triggering substances, such as quitting jobs, moving to a new house and ceasing to visit certain places. ${ }^{1,8}$ The disease has a progressive course, leading to symptomatology with reduced levels of the trigger exposure. 8,9
Correspondence: Alejandra de-la-Torre Neuroscience Research Group “NeURos”, Escuela de Medicina y Ciencias de la Salud, Universidad del Rosario, Carrera 24 \# 63C -

69, Bogotá, Colombia

Tel +57 3102482196

Email alejadelatorre@yahoo.com

Journal of Asthma and Allergy 2021:14 317-323 
The aim of this article is to report the case of a patient with multiple food allergies comorbid with MCS who was misdiagnosed on various occasions, resulting in a negative impact of their personal and social life.

\section{Case Presentation}

This case concerns a 43-year-old Colombian woman with a personal history of asthma and a family background of Still's disease. At the age of 21 years, she went to an alternative therapist for relief from severe diarrhea. The therapist administered an unknown intramuscular alternative medication, shortly after which the patient experienced a seizure-like episode. Ever since, the patient has experienced intermittent and progressive muscle weakness, dyspnea with minimal effort, and fatigue.

The patient initially consulted alternative medicine options and did not attend the allopathic medical specialist while her symptoms were intermittent and moderate for 12 years. She did not visit a general physician until her symptoms worsened and could no longer be managed. At 33 years of age, the patient was hospitalized in a tertiary referral center in Bogotá for two months, where numerous tests were performed, revealing various findings such as severe muscle fatigue in daily life activities, moderate physical deconditioning (functional class III), a moderate decrease in inspiratory and expiratory ventilatory muscle strength, low body mass index (BMI of $19.59 \mathrm{~kg} / \mathrm{m}^{2}$ ), State-Trait Anxiety Inventory score indicating a low state of anxiety (17 points) and medium trait anxiety (21 points), a Beck II depression test indicating minimum range depression (11 points), a change in quality of life in all its dimensions, a deficit in self-care in all of its components, and a change in phonatory pattern. The patient was treated with physical therapy, supervised pulmonary rehabilitation, and nutritional education. She improved her functional capacity and quality of life, but the moderate physical deconditioning persisted.

Over the next four years, the patient presented progressive arthralgia and worsening myalgia and began experiencing new symptoms such as whole body swelling, headache, and nausea after exposure to environmental factors such as pollution, aerosols, personal care products, solvents, paints, and car exhaust smoke. In the history of her illness, the patient presented numerous infections, anaphylactic-like reactions, and respiratory distress secondary to respiratory hypersensitivity with intolerance to bronchodilators. She was managed with respiratory therapies with no further complications.
Numerous specialists conducted various tests in which IgE always showed elevated levels. Due to her worsening symptoms and reports of nausea, vomiting, diarrhea, generalized pruritus, and urticaria related to several foods, the patient underwent allergy tests (RIDA qLine ${ }^{\circledR}$ Allergy, product number: A6342 Panel 3, method: indirect ELISA food-specific IgE antibody; R-Biopharm, Germany), which were positive for allergy to egg whites, starches, walnuts, chocolate, seafood, pork, milk, and food coloring.

In October 2015, the patient was hospitalized due to a new episode of acute respiratory failure. At the time, she reported new reactions to penicillin, crystalloids, nonsteroidal anti-inflammatory drugs, muscle relaxants, epinephrine, doxycycline, resins, dental products, deodorants, detergents, perfumes, and seafood. During hospitalization, she developed another four episodes of acute respiratory failure due to severe physical deconditioning. Diagnostic tests showed elevated C-reactive protein, hyponatremia, hypokalemia, vitamin D25 deficiency, and lung atelectasis. At that moment, she was diagnosed with laryngotracheitis.

In 2016, she continued presenting recurrent problems related to muscle weakness, fluid and electrolyte disorders, and allergic reactions to numerous substances. She, once again, underwent muscle and allergen tests (food-specific IgE antibody, tube-based AlaSTAT enzyme immunoassay; Diagnostic Products Corporation, Los Angeles, CA) that showed whole body weakness and deficient muscle flexibility and allergy to numerous environmental factors added to the previously diagnosed allergies (Dermatophagoides pteronyssinus, Dermatophagoides farinae, common meadow grass, fraxinus, homemade powder, penicillium, ragweed, cockroach, Timothy grass, grapes, pineapple, passionfruit, and tomato). Her doctors also conducted a work-up and ruled out the principal differential diagnosis (Table 1). She received three new diagnoses: severe hypersensitivity, upper respiratory tract hypersensitivity reaction, and extreme chemical allergy.

She consulted our department in 2017 with numerous complaints including headache, dizziness, nausea, loss of balance, somnolence, hyperacusis, sensation of hyperthermia, discoordination, asthenopia, chronic diarrhea, vomiting, and dysmenorrhea. The physical exam showed dry skin and throat, moderate physical deconditioning (class III), cognitive impairment with memory loss, chronic fatigue syndrome (CFS), malnutrition (BMI $18.5 \mathrm{~kg} / \mathrm{m}^{2}$ ), and a moderate reduction in respiratory muscle strength accompanied by unstable march, intolerance against certain odors, extreme respiratory tract hypersensitivity, congestive 
Table I Differential Diagnostic Approach

\begin{tabular}{|c|c|c|}
\hline Test & Result & Diagnosis Discarded \\
\hline Spirometry & $\begin{array}{l}\text { FVC: } 3.38 \text { (94\%) (normal) } \\
\text { FEVI: } 3.38 \text { (1 } 10 \%) \text { (normal) } \\
\text { FEVI/FVC: } 100 \text { (normal) }\end{array}$ & Restrictive pattern diseases \\
\hline $\begin{array}{l}\text { Chest } \\
\text { radiography }\end{array}$ & $\begin{array}{l}\text { Both lungs are clear and expanded with no infiltrates. Bibasilar } \\
\text { atelectasis are presented. Heart size within normal limits. No } \\
\text { pleural effusion. }\end{array}$ & $\begin{array}{l}\text { Eosinophilic pneumonia } \\
\text { Tuberculosis } \\
\text { Pulmonary infectious diseases } \\
\text { Sarcoidosis } \\
\text { Hypersensitivity pneumonitis }\end{array}$ \\
\hline $\begin{array}{l}\text { Complete } \\
\text { blood count }\end{array}$ & 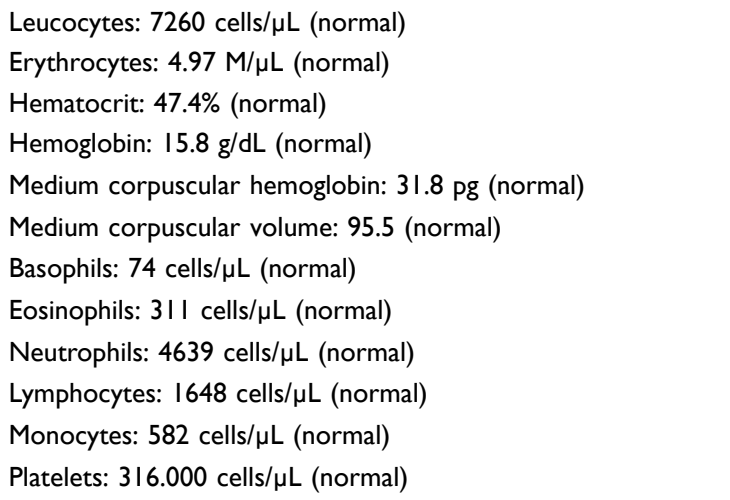 & $\begin{array}{l}\text { Anemia } \\
\text { Eosinophilic pneumonia } \\
\text { Lymphomas and leukemias }\end{array}$ \\
\hline $\begin{array}{l}\text { Kidney } \\
\text { function tests }\end{array}$ & $\begin{array}{l}\text { Creatinine: } 0.63 \mathrm{mg} / \mathrm{dL} \text { (normal) } \\
\text { Blood urea nitrogen: } 14.60 \mathrm{mg} / \mathrm{dL} \text { (normal) }\end{array}$ & Nephropathies \\
\hline $\begin{array}{l}\text { Metabolic } \\
\text { function test }\end{array}$ & $\begin{array}{l}\text { TSH: I.4I uUl/mL (normal) } \\
\text { T3 (total): } 1.25 \mathrm{ng} / \mathrm{mL} \text { (normal) } \\
\text { T4 (free): } 1.60 \mathrm{ng} / \mathrm{dL} \text { (normal) } \\
\text { Folic acid: } 15.5 \mathrm{ng} / \mathrm{mL} \text { (normal) } \\
\text { Vitamin BI2: } 409 \mathrm{pg} / \mathrm{mL} \text { (normal) } \\
\text { Total } 25 \text {-hydroxy vitamin D: I6.5 ng/mL (decreased) } \\
\text { Creatine phosphokinase: } 42 \mathrm{U} / \mathrm{L} \text { (normal) }\end{array}$ & $\begin{array}{l}\text { Hypo/hyperthyroidism } \\
\text { Graves' disease } \\
\text { Hashimoto thyroiditis } \\
\text { Folate deficiency (celiac disease) } \\
\text { Vitamin BI2 deficiency (celiac disease) } \\
\text { Muscular dystrophies } \\
\text { Rhabdomyolysis }\end{array}$ \\
\hline $\begin{array}{l}\text { Hepatic } \\
\text { diseases }\end{array}$ & $\begin{array}{l}\text { Iron levels: } 45 \mathrm{ug} / \mathrm{dL} \text { (normal) } \\
\text { Ferritin: } 48.4 \mathrm{ng} / \mathrm{mL} \text { (normal) } \\
\text { Transferrin: } 290 \mathrm{mg} / \mathrm{dL} \text { (normal) }\end{array}$ & $\begin{array}{l}\text { Hemochromatosis } \\
\text { Iron deficiency anemia secondary to intestinal absorption } \\
\text { disorders (celiac disease) } \\
\text { Liver disease } \\
\text { Iron poisoning }\end{array}$ \\
\hline $\begin{array}{l}\text { Inflammatory } \\
\text { and infectious } \\
\text { test }\end{array}$ & $\begin{array}{l}\text { Reactive } C \text { protein: }<1 \mathrm{mg} / \mathrm{dL} \text { (normal) } \\
\text { Galactomannan antigen: } 0.22 \text { (normal) }\end{array}$ & Aspergillosis \\
\hline $\begin{array}{l}\text { Immunologic } \\
\text { test }\end{array}$ & $\begin{array}{l}\text { C3 turbidometry: } 0.614 \mathrm{~g} / \mathrm{L} \text { (normal) } \\
\mathrm{C} 4 \text { turbidometry: } 0.406 \mathrm{~g} / \mathrm{L} \text { (mildly decreased) } \\
\text { IgG turbidometry: II.I g/L (normal) } \\
\text { IgA turbidometry: } 2.84 \mathrm{~g} / \mathrm{L} \text { (normal) } \\
\text { IgM turbidometry: } 0.994 \mathrm{~g} / \mathrm{L} \text { (normal) } \\
\text { IgE turbidometry: } 65 \mathrm{I} \mathrm{Ul} / \mathrm{mL} \text { (increase) } \\
\text { Rheumatoid factor: }<40 \mathrm{UI} / \mathrm{mL} \text { (normal) } \\
\text { Antinuclear antibodies: negative (normal) } \\
\text { Anti-DNAds antibodies: negative (normal) }\end{array}$ & $\begin{array}{l}\text { Immunodeficiencies: ataxia telangiectasia, hyper-lgM syndrome, } \\
\text { Wiskott-Aldrich syndrome, common variable } \\
\text { immunodeficiency, selective IgA deficiency } \\
\text { Systemic autoimmune diseases (rheumatoid arthritis and } \\
\text { systemic lupus erythematous) }\end{array}$ \\
\hline
\end{tabular}

Abbreviations: FVC, forced vital capacity; FEVI, forced expiratory volume in I second; TSH, thyroid-stimulating hormone; T3, triiodothyronine; T4, thyroxine; C3, complement component 3; C4, complement component 4; IgA, immunoglobulin A; IgE, immunoglobulin E; IgG, immunoglobulin G; IgM, immunoglobulin M; Anti-DNAds antibodies, anti-double-stranded DNA antibodies. 
pharynx, and expiratory breath sounds. The Quick Environmental Exposure and Sensitivity Inventory (QEESI) and Nethercott criteria were applied, reaching the diagnosis of MCS with severe deconditioning syndrome (Figure 1).

It is worth mentioning the patient's personal perception of the disease and its impact on her lifestyle. She had to abandon her architecture career and move out on numerous occasions to avoid triggers (construction materials, dust, varnishes, polish marble, among others). Currently, the patient is being treated with supplemental nutrition, respiratory and physical therapy, oxygen, avoidance of triggers, and for acute crises, corticosteroids, and terbutaline. Due to the difficulty in diagnosing and managing her case, the patient has a poor general condition and no desire for additional medical interventions.

\section{Discussion}

We present the case of a woman with multiple food allergies comorbid with MCS who presented multiorgan symptom involvement when exposed to numerous substances. According to Hojo et $\mathrm{al}^{10}$ and Nogué et $\mathrm{al},{ }^{11}$ the prevalence of MCS is higher in women (75-90.9\%) between 40 and 55 years of age. Studies have similarly documented a higher prevalence of food allergies in adult women, as well as sex disparities in the clinical manifestations and diagnoses, ${ }^{12}$ which could be explained by a hormone-dependent estrogen factor involved in the pathophysiology of MCS and food allergy, differences in the gut microbiome, and a genetic predisposition linked to sex. For example, there is evidence regarding an increase in hormonal fluctuations and pituitaryadrenal system sensitivity in women. Our patient matches the typical patient profile for MCS described in the literature. $^{10,11,13}$

Case reports have indicated that the symptoms of MCS are usually preceded by a well-defined "toxic event," which is usually exposure to a chemical agent, ${ }^{14}$ as was the case for our patient. Characteristically, patients show a progressive decrease in the stimulation threshold described in the toxicant-induced loss-of-tolerance theory. ${ }^{14}$ Thus, patients initially present a mild hypersensitivity-like reaction to a specific component; however, as tolerance decreases MCS symptoms become more common and disabling. For our patient, her constant exposure to foods and chemicals triggered recurrent and growing crises. ${ }^{11,14,15}$

There are biological, genetic, and psychiatric theories described in the current literature regarding the pathophysiology of MCS. ${ }^{11,15,16}$ A number of authors have proposed immune system abnormalities. Dantoft et $\mathrm{al}^{16}$ concluded that patients with MCS have an elevated proinflammatory cytokine profile, suggesting a chronic
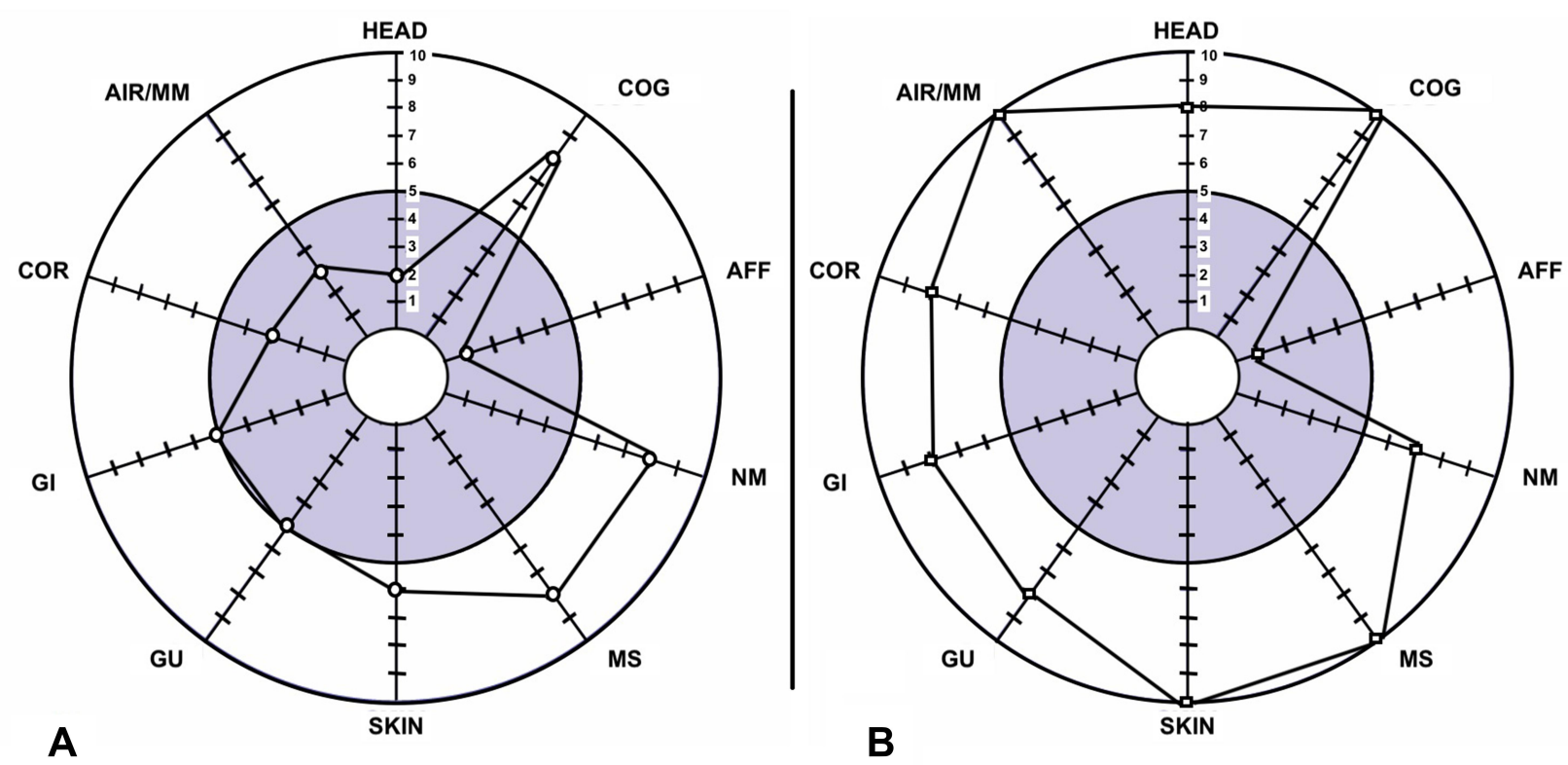

Figure I QEESI symptom Star2I: Illustration representing the symptom severity in our patient before and after the exposure event. Scale ranges from I to I0 in symptom severity. (A) Pre-exposure: circles represent pre-exposure. Each nomenclature represents a system. Circles were placed in the score corresponding to the symptoms before exposure. The most affected systems were cognitive, neuromuscular, and musculoskeletal. (B) Post-exposure: squares represent post-exposure. Each nomenclature represents a system. Squares were placed in the score corresponding to the symptoms after exposure. The symptoms showed a significant increase compared with the preexposure symptoms in all systems. The affective, neuromuscular, and cognitive systems were usually affected independently of exposure. 
inflammatory stage and elevated immune activation. Interleukin (IL)-4 is one of the ILs whose levels are increased in MCS and is usually associated with hypersensitivity reactions such as asthma, hay fever, and atopic dermatitis, which are comorbidities in MCS. ${ }^{16}$ However, the study by Dantoft et $\mathrm{al}^{16}$ showed that increased plasma IL-4 levels were not related to IgE isotype switching in MCS. The mechanisms of allergy and chemical sensitivity lead to similar systemic signs and symptoms, and the pathways involved might be similar. ${ }^{17}$ In our case, $\operatorname{IgE}$ showed significantly elevated levels over the course of years. Given her background of asthma, food allergy, and vitamin D25 deficiency, the persistently increased levels of $\mathrm{IgE}$ could be related to a type I hypersensitivity reaction. $^{18-20}$

It is important to differentiate between food allergy and intolerance, the former being mediated by immunological mechanisms against food-specific antigens, where multiple genetic, epigenetic, and environmental factors play a fundamental role, as with our patient. In contrast, food intolerance does not elicit an immune response and is triggered by toxins and pharmacological, metabolic, and undefined mechanisms. ${ }^{21,22}$

Under normal conditions, food antigens are recognized by the immune system but do not generate adverse immune responses. Regulatory $\mathrm{T}$ (Treg) cells are important tolerance mediators, suppressing immune responses through the production of immune-regulating cytokines (IL-10 and transforming growth factor beta) and the inhibition of naive $\mathrm{T}$-cell proliferation and differentiation into effector and memory CD4+ and CD8+ T cells. ${ }^{23,24}$ By contrast, Tregs are dysregulated in food allergies due to microbiome alterations, such as loss of commensal bacteria, which lead to a loss of protective mucosal response and alteration of intestinal barrier integrity. ${ }^{25}$ Commensals activate a MyD88/ROR- $\gamma$ t pathway in immature Treg cells to protect against food allergies, while dysbiosis impairs this regulatory response to promote disease. ${ }^{25}$ It would have been relevant to characterize the cellular profile in our patient to better elucidate the pathophysiological mechanisms involved in this case.

Food allergies should be diagnosed through the clinical manifestations elicited by food and tests that identify the specific antigens. In our patient's case, the diagnosis was reached by considering the patient's clinical reactivity to food and enzyme immunoassays (AlaSTAT and RIDA qLine) that confirmed the diagnosis and identified the specific antigens. ${ }^{21,22}$
If MCS is suspected, the QEESI should be employed as a screening tool, and the Nethercott criteria should be applied to establish the diagnosis. ${ }^{7,26,27}$ QEESI is a selfevaluation scale that helps identify the agents that trigger the disease and quantify its severity and repercussions on daily life, with a sensitivity of $92 \%$ and specificity of $95 \%{ }^{27}$ The Nethercott criteria includes the response to multiple chemically unrelated substances, chronicity, reproducibility of symptoms with exposure, manifestation of the syndrome with low levels of exposure, and improving or resolving the symptoms when the incitants are removed. ${ }^{6}$ In the present case, the diagnosis of MCS was reached by applying the QEESI and Nethercott criteria.

Patients with MCS have been considered to have a genetic or metabolic predisposition that conditions sensitization to these substances, even in subtoxic doses. ${ }^{1,2}$ Studies in the literature have reported an association between MCS and allergic diseases, CFS, anxiety, depression, among other conditions. ${ }^{11,28-30}$ In our patient's case, we documented asthma, multiple food allergies, and CFS.

Patients with MCS usually have a long history of the disease, during which they consult numerous doctors and undergo various inconclusive diagnostic tests and medical treatments without obtaining any improvement. ${ }^{11,31,32}$ In our patient's case, the initial suspicion was of an allergic reaction and asthma crisis that evolved into a deteriorated state. By the end, three different diagnoses related to baseline food allergy and MCS were reached: severe hypersensitivity, upper respiratory tract hypersensitivity reaction, and extreme chemical allergy. It is important to rule out principal differential diagnoses such as hypothyroidism, psychiatric diseases, hypersensitivity pneumonitis, immunodeficiencies, and autoimmune diseases that can mimic MCS. ${ }^{1,33}$

There are no practical guidelines on the treatment of this disease. Most physicians provide symptomatic treatment that is employed without clear evidence of its benefit in vivo or in vitro. ${ }^{32}$ Until now, the only management that has been shown to be beneficial in MCS is the patient eliminating or avoiding the triggers. ${ }^{31,32}$ In the present case, numerous respiratory, physical, and cardiopulmonary therapies were applied with no significant improvement. The patient underwent acute crisis management, which improved her acute symptoms; however, her chronic symptoms persisted, and her need for nutritional and oxygen supplementation progressively increased. This disease can generate a significant negative impact on patients' personal and social life, as has occurred in our case. ${ }^{11,31}$ 


\section{Conclusion}

MCS is a rare entity of unknown pathophysiology that requires better recognition of the current diagnostic criteria and the development of standardized treatment. Although it is difficult to diagnose due to its diverse symptomatology, it is important to consider MCS in the differential diagnosis. As in our case, MCS can be associated with allergic comorbidities that should be suspected when $\operatorname{IgE}$ levels are increased, even if the clinical manifestations overlap. As these entities could represent life-threatening conditions and negative factors for the patient's quality of life, it is important to promptly diagnose and treat them in a multidisciplinary manner. To the best of our knowledge, this is the first Latin American case of MCS comorbid with multiple food allergies.

\section{Abbreviations}

CFS, chronic fatigue syndrome; Treg cells, Regulatory $\mathrm{T}$ cells; MCS, multiple chemical sensitivity; BMI, body mass index; QEESI, Quick Environmental Exposure and Sensitivity Inventory; HEAD, head-related symptoms; COG, cognitive symptoms; AFF, affective symptoms; NM, neuromuscular symptoms; MS, musculoskeletal symptoms; SKIN, skin-related symptoms; GU, genitourinary symptoms; GI, gastrointestinal symptoms; COR, heart/chest-related symptoms; AIR/MM, airway or mucous membrane symptoms.

\section{Declaration of Patient Consent}

The authors certify that they have obtained all appropriate written patient consent forms. In the form, the patient gave consent for the images and clinical information to be reported in the journal. The patient understands that her name and initials will not be published, and all due efforts will be made to conceal her identity. This report required institutional approval to publish the case details and was approved by Universidad del Rosario's ethical committee under the reference DVO005 1475-CV1375.

\section{Acknowledgments}

We would like to thank the patient for granting permission to publish this information. We would also like to thank the Universidad del Rosario for financing the proofreading this manuscript and the Enago Group for the English edition.

\section{Author Contributions}

All authors significantly contributed to the reported study, whether in the conception, study design, execution, data acquisition, analysis, or interpretation. All authors participated in the drafting, revising, and critical review of the article, gave their final approval for the version to be published, agreed on the journal to which the article was to be submitted, and agreed to be accountable for all aspects of the work.

\section{Funding}

No funding was received to create this report.

\section{Disclosure}

The authors declare no conflicts of interest for this work.

\section{References}

1. Rossi S, Pitidis A. Multiple chemical sensitivity: review of the state of the art in epidemiology, diagnosis, and future perspectives. $J$ Occup Environ Med. 2018;60(2):138-146. doi:10.1097/ JOM.0000000000001215

2. World Health Organization. Report of the workshop on multiple chemical sensitivities (MCS), Berlin, Germany, 21-23 February 1996; 1996. Available from: https://apps.who.int/ iris/handle/10665/63109. Accessed March 23, 2021.

3. Phillips T. Debating the legitimacy of a contested environmental illness: a case study of multiple chemical sensitivities (MCS): debating the legitimacy of a contested illness. Sociol Health Illn. 2010;32 (7):1026-1040. doi:10.1111/j.1467-9566.2010.01255.x

4. Cullen MR. The worker with multiple chemical sensitivities: an overview. Occup Med. 1987;2(4):655-661.

5. Schwenk M. Multiple Chemical Sensitivity (MCS) - wissenschaftliche und gesundheitspolitische Aspekte. Laryngorhinootologie. 2004;83(11):763-765. doi:10.1055/s-2004-825948

6. Nethercott JR, Lee Davidoff L, Curbow B, Abbey H. Multiple chemical sensitivities syndrome: toward a working case definition. Arch Environ Occup Health. 1993;48(1):19-26. doi:10.1080/ 00039896.1993.9938389

7. Bartha L. Multiple chemical sensitivity: a 1999 consensus. Arch Environ Occup Health. 1999;54(3):147-149. doi:10.1080/0003989 9909602251

8. Yun M-J, Kang D-M, Lee K-H, Kim Y-K, Kim J-E. Multiple chemical sensitivity caused by exposure to ignition coal fumes: a case report. Ann Occup Environ Med. 2013;25(1):32. doi:10.1186/20524374-25-32

9. Miller CS, Gammage RB, Jankovic JT. Exacerbation of chemical sensitivity: a case study. Toxicol Ind Health. 1999;15(3-4):398-402. doi:10.1177/074823379901500313

10. Hojo S, Mizukoshi A, Azuma K, Okumura J, Mizuki M, Miyata M. New criteria for multiple chemical sensitivity based on the quick environmental exposure and sensitivity inventory developed in response to rapid changes in ongoing chemical exposures among Japanese. PLoS One. 2019;14(4):e0215144. doi:10.1371/journal. pone. 0215144

11. Nogué XS, Dueñas Laita A, Ferrer Dufol A, Fernández Solà J. Sensibilidad química múltiple. Med Clín. 2011;136(15):683-687. doi:10.1016/j.medcli.2010.04.010

12. Pali-Schöll I, Jensen-Jarolim E. Gender aspects in food allergy. Curr Opin Allergy Clin Immunol. 2019;19(3):249-255. doi:10.1097/ ACI.0000000000000529 
13. Lax MB, Henneberger PK. Patients with multiple chemical sensitivities in an occupational health clinic: presentation and follow-up. Arch Environ Occup Health. 1995;50(6):425-431. doi:10.1080/ 00039896.1995.9935978

14. Rossi S, Vanacore N, Comba P. Multiple chemical sensitivity: pursuit of a scientific consensus, need for a public health response. Ann Ist Super Sanita. 2019;55(4):319-322. doi:10.4415/ANN_19_04_03

15. Winder C. Mechanisms of multiple chemical sensitivity. Toxicol Lett. 2002;128(1-3):85-97. doi:10.1016/S0378-4274(01)00536-7

16. Dantoft TM, Elberling J, Brix S, Szecsi PB, Vesterhauge S, Skovbjerg S. An elevated pro-inflammatory cytokine profile in multiple chemical sensitivity. Psychoneuroendocrinology. 2014;40:140-150. doi:10.1016/j.psyneuen.2013.11.012

17. Meggs WJ. Mechanisms of allergy and chemical sensitivity. Toxicol Ind Health. 1999;15(3-4):331-338. doi:10.1177/074823379901500307

18. Gordon BR. Approaches to testing for food and chemical sensitivities. Otolaryngol Clin North Am. 2003;36(5):917-940. doi:10.1016/S0030-6665(03)00059-8

19. Fukuyama T, Ueda H, Hayashi K, et al. Detection of low-level environmental chemical allergy by a long-term sensitization method. Toxicol Lett. 2008;180(1):1-8. doi:10.1016/j.toxlet.2008.05.001

20. Matsui T, Tanaka K, Yamashita H, et al. Food allergy is linked to season of birth, sun exposure, and vitamin D deficiency. Allergol Int. 2019;68(2):172-177. doi:10.1016/j.alit.2018.12.003

21. De Martinis M, Sirufo MM, Viscido A, Ginaldi L. Food allergy insights: a changing landscape. Arch Immunol Ther Exp (Warsz). 2020;68(2):8. doi:10.1007/s00005-020-00574-6

22. De Martinis M, Sirufo MM, Suppa M, Ginaldi L. New perspectives in food allergy. Int $J$ Mol Sci. 2020;21(4):1474. doi:10.3390/ ijms21041474

23. Bauer RN, Manohar M, Singh AM, Jay DC, Nadeau KC. The future of biologics: applications for food allergy. J Allergy Clin Immunol. 2015;135(2):312-323. doi:10.1016/j.jaci.2014.12.1908

24. Satitsuksanoa P, Jansen K, Głobińska A, van de Veen W, Akdis M. Regulatory immune mechanisms in tolerance to food allergy. Front Immunol. 2018;9:2939. doi:10.3389/fimmu.2018.02939

25. Abdel-Gadir A, Stephen-Victor E, Gerber GK, et al. Microbiota therapy acts via a regulatory $\mathrm{T}$ cell $\mathrm{MyD} 88 / \mathrm{ROR} \gamma \mathrm{t}$ pathway to suppress food allergy. Nat Med. 2019;25(7):1164-1174. doi:10.1038/ s41591-019-0461-z
26. Skovbjerg S, Berg ND, Elberling J, Christensen KB. Evaluation of the quick environmental exposure and sensitivity inventory in a danish population. J Environ Public Health. 2012;2012:1-10. doi:10.1155/2012/304314

27. Miller CS, Prihoda TJ. The environmental exposure and sensitivity inventory (EESI): a standardized approach for measuring chemical intolerances for research and clinical applications. Toxicol Ind Health. 1999;15(3-4):370-385. doi:10.1177/074823379901500311

28. Caress S, Steinemann A. Asthma and chemical hypersensitivity: prevalence, etiology, and age of onset. Toxicol Ind Health. 2009;25 (1):71-78. doi:10.1177/0748233709102713

29. Hojo S, Mizukoshi A, Azuma K, et al. Survey on changes in subjective symptoms, onset/trigger factors, allergic diseases, and chemical exposures in the past decade of Japanese patients with multiple chemical sensitivity. Int J Hyg Environ Health. 2018;221 (8):1085-1096. doi:10.1016/j.ijheh.2018.08.001

30. Bornschein S, Hausteiner C, Zilker T, Förstl H. Psychiatric and somatic disorders and multiple chemical sensitivity (MCS) in 264 'environmental patients. Psychol Med. 2002;32(8):1387-1394. doi:10.1017/S0033291702006554

31. Gibson PR, Elms AN-M, Ruding LA. Perceived treatment efficacy for conventional and alternative therapies reported by persons with multiple chemical sensitivity. Environ Health Perspect. 2003;111 (12):1498-1504. doi:10.1289/ehp.5936

32. De Luca C, Raskovic D, Pacifico V, Thai JCS, Korkina L. The search for reliable biomarkers of disease in multiple chemical sensitivity and other environmental intolerances. IJERPH. 2011;8(7):2770-2797. doi:10.3390/ijerph8072770

33. Labarge XS, McCaffrey RJ. Multiple chemical sensitivity: a review of the theoretical and research literature. Neuropsychol Rev. 2000;10 (4):183-211. doi:10.1023/a:1026460726965

\section{Publish your work in this journal}

The Journal of Asthma and Allergy is an international, peer-reviewed open-access journal publishing original research, reports, editorials and commentaries on the following topics: Asthma; Pulmonary physiology; Asthma related clinical health; Clinical immunology and the immunological basis of disease; Pharmacological interventions and new therapies. The manuscript management system is completely online and includes a very quick and fair peer-review system, which is all easy to use. Visit http://www.dovepress.com/testimonials.php to read real quotes from published authors. 